\title{
Canadian Forestry Education - Where Are We Heading?
}

by

\author{
J.V. Thirgood
}

During the past thiry years, since my first exposure to North American forestry education, there has been an almost continuous debate as to objectives and purposes. An outside observer might be excused if he were to ask if we know where we are going.

Back in 1960, at the Fifth World Congress, the late Svend Heiberg, distinguished Danish-American forestry educator, in a wide ranging paper ${ }^{2}$, discussed future needs in professional education. His message remains germane today and we might question how far we have followed the trail he charted. He pointed out that when David Douglas visited the Pacific Northwest in 1825, he could not foresee that the tree that was to carry his name was to become the most prized of the many exotic trees that 19th century plant collectors were to carry back to Europe. Nor could he foresee that the Columbia River ecotype he took back to Kew Gardens in England would prove the most useful of all the provenances that would be planted in Europe. At that time the modern city of Vancouver was covered by a majestic forest that most likely had never been penetrated by white men.

Almost coincident with Douglas' introduction of his fir, in Hungary the Selmec Forestry Faculty, predecessor to the Sopron, was founded in 1808. Prior to this the only forestry academy was at Venice; Heinrich Cotta's master school at Tharant became the Royal Saxonian Forestry Academy only in 1816. These were the precursors of modern university level forestry education. They date from just 180 years back but were part of a different world.

In their different spheres Douglas and Cotta were pioneers of a new era. Just as Douglas could not have anticipated the consequences of his tree introduction, so Cotta and the other early forestry educators could hardly have foreseen that just two Douglas fir rotations later 20,000 students would be enrolled in forestry.

In this short time span 1808-1989, the world of Douglas and Cotta had been transformed. Following the Napoleonic wars and the Congress of Vienna, men looked forward with confidence to an unsurpassed development in culture, science, technology, trade and increasing world population, and most importantly, to a time of greater human freedom, dignity and rights. Men of vision felt their work would have far reaching consequences and to a great extent their expectations were fulfilled.

In contrast to the optimism of the early 19th century, young people today do not look out on a world that appears to be steadily unfolding in an orderly and apparently preordained manner. Many are filled with pessimism, I believe unfounded, but rightly or wrongly they see instability and uncertainty and even doubt the long-term future of our planet

Professor of Forestry, University of British Columbia

${ }^{2}$ Svend O. Heiberg. Post-graduate study for World Forestry. Fifth World Forestry Congress. Seattle. 1960 as the home of man. In place of idealism and public service we have the doctrines of self-interest and materialistic consumerism. But, as in Cotta's day, though in a world far removed from that of the 19th century forestry pioneers, our students must be educated so that their vision and work can be of lasting significance.

Heiberg discussed the need for world cooperation and clearly believed that our responsibility toward humanity was on a par with our responsibility to our nation. He stated that we need leaders in every walk of life, men who can look beyond the needs of tribe, nation or race - he might well have included corporation, province and country - and regard the welfare of the world as their objective. He was, of course, an internationalist writing at the height of the Cold War. He saw the need for cooperation, not only in narrow professional terms, but as a means of making a better world to live in and as a means to the understanding and cooperation essential for man's very existence. His concern was with how forestry education could help produce these people the future leaders. We might ask ourselves how far we have progressed toward achieving Heiberg's vision during the subsequent almost 30 years, a full professorial rotation, and how far our educational process still languishes in parochial concerns.

The dominant trend in education this century, no less in forestry than in other disciplines, has been an increasing emphasis on mass education. The few men enrolled in Cotta's academy, or even, in the later Canadian context, who studied under Fernow at Toronto, have exploded into the thousands who are today enrolled in forestry programmes world wide. This expansion is not only a reflection of the growth of the profession but an expression of the general expansion of education. Today there is a firm belief that knowledge is our most valuable resource and that the more people share this knowledge the better will be the world we inhabit. We take this for granted but it is a revolutionary idea in the history of mankind.

As Heiberg pointed out, this essentially egalitarian thesis, from which many of us have benefitted personally, has not been without cost. By adopting pedagogic methods to meet the demands of mass education rather than the education of a privileged elite, we can hamper the development of the more able students. In opening the door to the many we must not neglect the talent of the few. It is not by chance that in egalitarian North America, with its emphasis on educational opportunities for a considerable section of society and a supermarket approach to the packaging of undergraduate education, post-graduate education has been most developed. The tradition of educational freedom and loosely structured undergraduate learning characteristic of the ancient European universities and some of the long established institutions of North America, with its vision of an educated person as one with some understanding of things as they were, a well rounded knowledge of things as they are, and a vision 
of things as they might be; and as one who can think independently, read critically, and write clearly, suffers adversely under mass education. A system of personal or small group tutoring and personal study does not lend itself to large student intakes.

World-wide, the curricula of university forestry schools are characterized by being crammed with courses that are either inappropriate to the university and/or are directed to the perceived job needs of the region the school serves. Despite the increasing movement of students between countries and particularly from the developing world there are few forestry schools that truly look upon the world as their bailiwick. Provincialism prevails.

The contrast with other professions - engineering, medicine, architecture - is striking. Other than slight modifications to meet local taste and tradition, a modern bridge or building is almost identical whether it is in Africa, Asia, Europe, or America. Not long ago, with folk medicine, local treatments for ailments varied widely, but modern medicine follows universal principles and is applied uniformly. Yet this medieval situation still prevails in forestry for, notwithstanding similar circumstances and similar stand structures, forest stands under identical site and economic constraints may have very variable treatment. These differences may reflect political systems and resource management traditions, but even when technical concerns are involved, where we might expect the most logical concept to be accepted and applied, this is not so, and students may not even be introduced to these alternatives. This lack of acceptance of universal concepts surely reflects excessive parochialism but it also both reflects and results in a lack of broadly based education for the student.

In the second half of the 20th century, particularly in North America, we have seen the triumph of Cartology ${ }^{3}$, and forest education has seen a shift from the seasoned foresterteacher to the forest scientist-researcher-teacher and, concomitantly, increased, even narrow, specialization. Today's process too easily turns potential resource managers into resource scientists and can have profound effects on the product of the educational system.

First and foremost, forestry academies are professional institutions and, as such, have responsibilities to students, profession and society similar to such university faculties as engineering, agriculture, medicine, law and education. Their central purpose is the undergraduate education of forest resource managers. This is easily lost sight of when teaching staff are driven toward research oriented objectives in pursuit of academic esteem and stature.

A difficulty is that forestry is a form of husbandry - albeit founded in part on science - and husbandry can only be taught by husbandmen. Too often we take refuge in the underlying sciences, neglecting the empirical nature of much of forestry, the synthesis of accumulated experiential knowledge, past and present, or, alternatively, at the other extreme, we stress the technical how rather than the social why.

When the chosen, if not sole route into forestry teaching is through post-graduate education, and the publication list becomes the criterion of academic excellence, students are no longer necessarily exposed to men of broad vision and experience, and are often burdened with narrowness of detail

${ }^{3}$ Defined as the worship of pieces of paper, particularly doctoral diplomas. Jack C. Westoby. The Purpose of Forests. Blackwell. 1987 and preoccupation with research - the pursuit of new knowledge of variable significance - to the neglect of the synthesis of established world knowledge that often does not originate in the current issues of a refereed research journal. In consequence, all too often the training offered to our undergraduate students is confined within the perceived immediate regional need and conditions or the research laboratory and interests of the individual professor. In all this there is little room for the general education that is desirable to broaden the outlook of the individual and provide for a perspective of the forest and forestry in relation to human culture. Increasingly we forget that the one unique function of the university, the reason for its existence and duplicated no where else, is teaching.

Much depends upon the quality of the pre-forestry educational exposure. If this includes a thorough submersion in a cultural curriculum in the broadest sense, or if the forestry school is part of a larger university with the cultural advantages of the best of such institutions, or if it has a strong leavening of mature age students who can see past the trees, then all may be well, presupposing that our students are encouraged, and importantly, given the opportunity, to participate in the general intellectual and cultural life of the university community. All too often students in professional faculties tend to form separatist cliques within the body-academic. This may develop camaraderie and esprit-de-corps, but it can prove disastrous to the broader educational objective. It is no wonder that academics in other disciplines sometimes accuse the forestry school of providing vocational training rather than academic education. In the old residential collegiate framework interdisciplinary mixing and learning by osmosis were unavoidable - this in not necessarily so in the modern compartmented 9 to 5 multiversity.

There are great differences in the curricula of forestry schools world-wide, much more so than in engineering and medicine. Countries where forestry practice is well advanced place greater emphasis on silviculture and non-market values. Where forestry is still in the exploitive phase there is emphasis on harvesting and utilization, and engineering and inventory techniques - a reflection of the strong vocational flavour referred to earlier. This lack of acceptance of universal concepts surely reflects excessive parochialism and may meet the immediate need but it also reflects and contributes to the lack of broadly based training for the truly gifted students.

While, frequently there is excellent provision for the forest scientists of tomorrow, we need better provision for those who are destined to be the leaders. The overall process is designed to culminate in a pointy-headed elite who will finish up teaching or in research. Those with broader horizons are less well provided for, the notable exceptions most often have had to fight the system to achieve their academic goals. A broadly based programme should be provided for such students, or alternatively, they should be afforded the utmost freedom in course selection to meet their individual needs and interests. Fortunate are those who come in contact with sympathetic professors. It goes without saying that students should be selected on the basis of a sense of vocation and not merely on their academic record. A pre-admission interview is essential as also is prior woods experience. Perhaps we should adopt the practice of many agricultural schools whereby students are accepted and are then required to obtain a full year's approved work experience before admission to classes. Similarly, as befits a professional school, forestry education would benefit, not least in the greater maturity of the students, if organized as an upper division or graduate school within the university. 
Students, particularly those of mature age, should be able to formulate their own programmes with the assistance of faculty advisors. But this is an ideal situation except at the post-graduate level. Similarly the university should be a community of free-thinking scholars in a common search for truth and enlightenment, but in these days when we hear university presidents talking about the university as an engine of the economy, we know this ideal is far from reality. Most students need direction - and in most cases, though they may not admit it, all but a few and those particularly of mature age, prefer this to taking initiative and personal responsibility. Again, although they may not admit it, many undergraduates prefer assignments and mid-term tests and quizzes - socalled continuous evaluation - to self-directed study. Professors soon learn that it is easier to direct and require than to advise and encourage. This is unfortunate for those individuals who seek time to think but are faced with a sea of busy work and course requirements. Under such conditions, while it may meet the needs of the mass-university, the exceptional students' educational development is slowed considerably and their ability to read critically, assess objectively and write lucidly, all skills that require cultivation, may well suffer. These exceptional students need to be given as much freedom as possible so that they may be challenged not only in meeting routine requirements but in meeting their own needs.

We probably do a satisfactory job for those able students with strictly specialized interests, such as lead them to a research career, but the second group with broader horizons and wider interests are less well provided for. It is from this group that we may expect men to rise to professional leadership, and whose influence may extend beyond the constraints of professional forestry. Though it must be admitted that too often the reverse seems to have been the case.

Such students may be attracted to courses in sociology, human relations, history, geography, economics, law or international relations, all within the context of their forestry education. They want to develop not only as foresters but in their understanding of the human condition and of the needs of our civilization. It is from these that will arise those who can present, explain and sometimes defend the place of forestry in society, while also interpreting society's needs and desires to the profession.

Such individuals require exposure to other than academic researchers, and here is the nub. For several reasons, some valid, some less so, as indicated earlier, in North American universities and perhaps elsewhere, particularly in those countries where American university traditions have been transplanted through the varied processes of foreign

\section{The Annual Meeting Schedule}

1990 - August 20-24, Fredericton, N.B. Theme: In Pursuit of Excellence in the Forestry Profession

1991 - September 22-26, Toronto, Ontario

1992 - Vancouver, B.C. aid, the selection of faculty members today emphasizes academic background and scholarly achievement far more than it does professional experience, no matter how distinguished or wide ranging. In contrast, earlier this century a record of substantial professional accomplishment was at least as important a credential to be allowed the privilege of classroom contact with forestry students as was scholarly accomplishment, most often indeed such a record was more important. The appointment of the director of a forestry school from other than the pinnacle of the practicing profession was unthinkable. The basic principle of almost universal application was that all university instructors, no matter their area of teaching responsibility, must have significant experience as divisional foresters - in effect a prior high-achieving career in forestry practice. They were appointed on the basis of their proven achievement, rather than, as today, on their presumed potential. Such men were able to salt their science and theory with their personal life experience and, whisper it, bring an air of reality to their teaching. Today too often we have theorists teaching that which they have never practiced. The Ph.D., the publication list, the refereed journal and the research grant reign supreme.

Nevertheless, it is doubtful whether this category of students, the future leaders, need technical courses that aim at mechanical application to any great extent. The concern should be with principles. In most forestry related subjects these principles are universal while applications are legion and are to be developed in the context of local situations.

Additional to personalized study, seminars lend themselves to the needs of such students. These provide opportunity for exposure to outside lecturers, visitors, local practitioners, forest scientists and specialists. Such stimulations may add little to factual content but they add vitality and variety. The divergent contacts and impressions motivate the gifted student and encourage him to seek further information independently - provided time is allowed in the curriculum. A university student must have time to think.

But none of these compare in educational importance with the ability of teaching staff to inspire and guide students. The important thing is that the cream of our forestry students receive educational opportunities to fit them for leadership and to develop their capacities in the widest context possible. A professor is one who thinks otherwise. Fortunate are those students who are exposed to faculty whose divergent views and backgrounds encourage stimulation, controversy and fertile thinking and will always make sure the rush hour is going in the opposite direction. As Northrop Fry has said "Education is a matter not of filling buckets but of lighting fires."

\section{Woodlot Service (1978) Ltd.}

\section{"All Matters Pertalning to Forestry"}

\section{GORDON B. YOUNG, B.Sc.F., M.F.} Registered Professional Forester

320 Maple Street

Bus.: $506-472-3396$

Fredericton, N.B. E3A 3R4
Home: $506-472-7721$ 